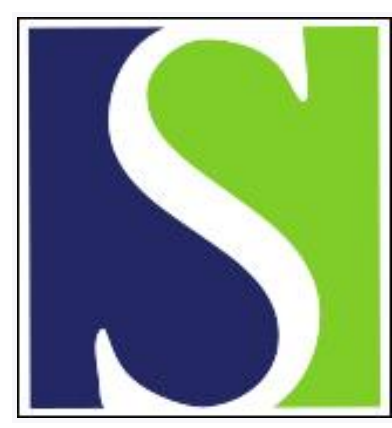

Scand J Work Environ Health 1990;16(4):247-251

https://doi.org/10.5271/sjweh.1788

Issue date: 01 Aug 1990

Mortality of cellulose fiber production workers.

by Lanes SF, Cohen A, Rothman KJ, Dreyer NA, Soden KJ

Affiliation: Epidemiology Resources Inc, Chestnut Hill, Massachusetts 02167.

This article in PubMed: www.ncbi.nlm.nih.gov/pubmed/2389131 


\title{
Mortality of cellulose fiber production workers
}

\author{
by Stephan F Lanes, PhD, ${ }^{1}$ Aaron Cohen, $\mathrm{MPH},{ }^{1}$ Kenneth J Rothman, $\mathrm{DrPH},{ }^{1}$ \\ Nancy A Dreyer, $\mathrm{PhD},{ }^{1}$ Kevin J Soden, $\mathrm{MD}^{2}$
}

\begin{abstract}
LANES SF, COHEN A, ROTHMAN KJ, DREYER NA, SODEN KJ. Mortality of cellulose fiber production workers. Scand $J$ Work Environ Health 1990;16:247-51. Mortality was studied among 1271 employees of a cellulose fiber production plant in Rock Hill, South Carolina, in the United States. Each subject was employed for at least three months between 1 January 1954 and 1 January 1977 in jobs that entailed exposure to the highest concentrations of methylene chloride. In the cohort 122 deaths were identified through 1 September 1986, and mortality rates for the cohort were compared with mortality rates for York County, South Carolina. Deficit mortality was observed for cancers of the respiratory system, breast, and pancreas and from ischemic heart disease. Excess mortality was observed for cancers of the buccal cavity and pharynx and the liver and biliary tract, and for melanoma as well. The largest relative excess was for liver and biliary tract cancers. There were only four deaths in this category; however, three of the four deaths were cancer of the biliary tract ( 3 observed, 0.15 expected, standardized mortality ratio 20 ).
\end{abstract}

Key terms: buccal cavity, bile duct, ischemic heart disease, liver, melanoma, methylene chloride, neoplasms, pancreas, pharynx, solvents.

Methylene chloride (dichloromethane) is a chlorinated solvent with many industrial and commercial applications, including metal cleaning, paint stripping, chemical processing, and the decaffeination of coffee (1). In the early 1970 s, inhalation of methylene chloride was found to decrease arterial oxygen content by increasing carboxyhemoglobin, and this finding stimulated interest in research on a possible relationship between methylene chloride and ischemic heart disease (2). More recently, bioassays have yielded evidence indicating that methylene chloride is carcinogenic in mice and rats (3). An epidemiologic study of workers exposed to methylene chloride in the production of photographic film found no excess of ischemic heart disease, but it did report an excess of pancreatic cancer (4). These studies have generated interest in the possible carcinogenic effect of methylene chloride on humans.

In this article we report an update of a study with a previously assembled cohort of textile workers exposed to methylene chloride in the production of cellulose triacetate fiber from 1954 until 1977 (5). Although exposure measurements for most of the study period are unavailable, existing data from the 1970s suggest that the exposure levels were substantially greater for this cohort $(5,6)$ than for a cohort of photographic film manufacturers (4).

\footnotetext{
1 Epidemiology Resources Inc, Chestnut Hill, Massachusetts, United States.

${ }^{2}$ Hoechst Celanese Corporation, Textile Fibers Group, Charlotte, North Carolina, United States.
}

Reprint requests to: Dr SF Lanes, Epidemiology Resources Inc, 826 Boylston Street, Chestnut Hill, MA 02167, USA.

\section{Subjects and methods}

We studied a previously assembled cohort of 1271 workers exposed to methylene chloride in the production of cellulose triacetate fiber at a fiber manufacturing plant in Rock Hill, South Carolina, in the United States (5). The plant produced cellulose triacetate fiber throughout the study period, but ceased production in 1986. The cohort was assembled in 1977 and comprised people employed in the preparation or extrusion areas for at least three months between 1 January 1954 and 1 January 1977 (5). Employment in the preparation and extrusion areas entailed the greatest exposures to methylene chloride (5). From previous investigators we obtained a data file for the cohort that included the following information for each employee: first and last name, social security number, date of birth, dates of hire and termination, sex, and race. We updated the information on employment status from personnel and benefits records.

Methylene chloride was the major solvent exposure to employees in the cellulose triacetate production process, but methanol was also used in a ratio of approximately one part methanol to ten parts methylene chloride, and acetone was used as well (5). An industrial hygiene survey conducted in 1977 reported 8-h time-weighted average (TWA) exposures ranging from below detectable limits up to $1700 \mathrm{ppm}$ for methylene chloride, $1600 \mathrm{ppm}$ for acetone, and $140 \mathrm{ppm}$ for methanol among the workers in the extrusion and preparation areas (6). Respirators were not used until 1984. Detailed work history data are available only for 356 active employees and 119 employees who terminated their employment after 1979.

We ascertained vital status of the cohort for the period 1 January 1954 through 1 September 1986 by 
comparing the cohort roster with decedent records of the plant, the national death index, and the Social Security Administration (7, 8). A nosologist reviewed the death certificates and assigned codes to the underlying cause of death and contributing causes of death in accordance with the ninth revision of the International Classification of Diseases (ICD) (9). The 1149 employees not identified as deceased were assumed to be living at the end of the study period.

We compared the mortality of the cohort with the population of York County, South Carolina, which was the county of residence for $95 \%$ of the cohort

Table 1. Distribution of the cohort by vital status, sex, and race.

\begin{tabular}{lrrr}
\hline & Dead & Alive & Total \\
\cline { 2 - 4 } Men & & & \\
White & 81 & 406 & 487 \\
Nonwhite & 12 & 52 & 64 \\
Women & & & \\
White & 29 & 586 & 615 \\
Nonwhite & - & 105 & 105 \\
\hline Total & 122 & 1149 & 1271 \\
\hline
\end{tabular}

Table 2. Observed $(O)$ and expected $(E)$ numbers of deaths from selected causes. (SMR = standardized mortality ratio, $95 \%$ $\mathrm{Cl}=95 \%$ confidence interval)

\begin{tabular}{|c|c|c|c|c|}
\hline & 0 & $\varepsilon$ & SMR & $95 \% \mathrm{Cl}$ \\
\hline All causes & 122 & 141.94 & 0.86 & $0.71-1.03$ \\
\hline \multicolumn{5}{|l|}{ Neoplasms } \\
\hline $\begin{array}{l}\text { Buccal cavity pharynx } \\
\text { Biliary passages \& liver } \\
\text { Melanoma } \\
\text { Bronchus, trachea \& lung } \\
\text { Breast } \\
\text { Pancreas }\end{array}$ & $\begin{array}{l}2 \\
4 \\
2 \\
8 \\
2 \\
1\end{array}$ & $\begin{array}{r}0.87 \\
0.70 \\
0.88 \\
10.11 \\
3.32 \\
1.54\end{array}$ & $\begin{array}{l}2.31 \\
5.75 \\
2.28 \\
0.79 \\
0.60 \\
0.65\end{array}$ & $\begin{array}{l}0.39-7.60 \\
1.82-13.78 \\
0.38-7.51 \\
0.37-1.50 \\
0.10-1.99 \\
0.03-3.20\end{array}$ \\
\hline Accidents & 21 & 12.77 & 1.64 & $1.05-2.47$ \\
\hline $\begin{array}{l}\text { Hypertension without } \\
\text { heart disease }\end{array}$ & 2 & 0.62 & 3.20 & $0.54-10.66$ \\
\hline Cerebrovascular disease & 5 & 8.90 & 0.56 & $0.21-1.25$ \\
\hline Ischemic heart disease & 31 & 34.33 & 0.90 & $0.62-1.27$ \\
\hline $\begin{array}{l}\text { Nonmalignant respiratory } \\
\text { disease }\end{array}$ & 4 & 6.04 & 0.66 & $0.21-1.60$ \\
\hline Suicide & 3 & 4.86 & 0.62 & $0.16-1.68$ \\
\hline
\end{tabular}

Table 3. Characteristics of the four employees who died of liver and biliary tract cancer.

\begin{tabular}{|c|c|c|c|c|}
\hline Sex & $\begin{array}{c}\text { Age } \\
\text { (years) }\end{array}$ & Cause ${ }^{a}$ & Autopsy & $\begin{array}{l}\text { Medical } \\
\text { record } \\
\text { confirmation }\end{array}$ \\
\hline Male & 59 & $\begin{array}{l}\text { Cholangiocarcinoma } \\
\text { of ampulla Vater (156.2) }\end{array}$ & No & Yes \\
\hline Male & 67 & $\begin{array}{l}\text { Adenocarcinoma } \\
\text { of liver (155.2) }\end{array}$ & Yes & No \\
\hline Female & 60 & $\begin{array}{l}\text { Cholangiocarcinoma of } \\
\text { hepatic and common } \\
\text { bile ducts (156.1) }\end{array}$ & No & Yes \\
\hline Female & 47 & $\begin{array}{l}\text { Cholangiocarcinoma of } \\
\text { common bile duct }(155.1)\end{array}$ & No & Yes \\
\hline
\end{tabular}

a Code of the International Classification of Diseases, ninth revision, in parentheses. members. During the study period, the cohort constituted less than $4 \%$ of the York County population. Death rates for causes of death other than malignancies were unavailable for the reference population for years prior to 1962 ; therefore 1962 rates were used for the years 1954-1961. We used the occupational cohort mortality analysis program (OCMAP) to sum person-years within categories of age (five-year intervals), calendar period (five-year intervals), race (white/nonwhite), and sex and to compute standardized mortality ratio (SMR) values (10). We computed exact $95 \%$ confidence limits for the SMR values using the mid-p method (11).

\section{Results}

The demographic composition of the cohort was predominantly white $(87 \%)$ with a slight majority of women $(57 \%$ ) (table 1). Ninety-six percent of the employees were less than 40 years of age when they were hired. Fifty-three percent of the cohort was employed for at least 10 years, although only $34 \%$ of the persontime was contributed to this category of duration of employment. Everyone was hired after 1 January 1948. The hiring rate was stable over the study period and resulted in only $26 \%$ of the person-time contributed by the cohort to the category of 20 or more years since first employment.

We identified 122 deaths in 29960 person-years, and we obtained death certificates for $97 \%$ of the decedents (118 of 122). We computed effect estimates for 62 causes of death. For most causes of death, the SMR values were close to the null value and therefore indicated no association. Table 2 presents the SMR and $95 \%$ confidence interval $(95 \% \mathrm{CI}$ ) for diseases for which we observed an excess or deficit of at least one death. We have also included the results for pancreatic cancer in table 2 because it was the only cause of death reported to occur in excess in a previous study of a cohort exposed to methylene chloride (4).

We observed excess mortality for the following types of cancer: cancer of the buccal cavity and pharynx, cancer of the liver and biliary passages, and melanoma (table 2). We observed deficit mortality for cancer of the respiratory system, breast, and pancreas. Among the noncancer causes of death, we observed excess mortality from accidents and hypertension without heart disease. We observed deficit mortality for cerebrovascular disease, ischemic heart disease, and nonmalignant respiratory disease.

Because of the strong association with cancer of the liver and biliary passages, we conducted further analyses for this cause of death in which we stratified by time since first employment at the plant $(<20$ years, $\geq 20$ years) and duration of employment at the plant ( $<10$ years, $\geq 10$ years). We used employment as a marker for exposure in this analysis because complete 
work histories were unavailable for the entire cohort. This approach can overestimate both the duration of exposure (if there was employment in unexposed areas) and time since first exposure (if the first job was not in an exposed area). All of the deaths from cancer of the liver and biliary passages occurred among the workers with ten or more years of employment and at least 20 years since first employment ( 4 observed/ 0.35 expected).

We investigated further the medical histories of the four employees who died of cancer of the liver and biliary tract (table 3). For three decedents, the tumor sites were confirmed by medical records as intrahepatic and common bile duct, common bile duct, and ampulla of Vater. For the remaining death, no medical record could be obtained. This person was, however, the only decedent in the group for whom an autopsy had been performed, and the death certificate diagnosis was adenocarcinoma of the liver. Fortuitously, the three employees who died of biliary cancer were in the group of 119 employees for whom we obtained complete work histories. The approximate durations of employment in jobs entailing substantial exposure to methylene chloride for the three biliary cancer deaths were 28 years, 20 years, and less than 1 year.

In general, it is desirable to estimate effects separately for different diseases. Unfortunately, cancer of the liver is combined with cancer of the biliary passages in the mortality data from York County, South Carolina, and therefore we could not use these data to compute the number of deaths expected from cancer of the biliary tract. The surveillance, epidemiology, and end results (SEER) program, however, provides detailed vital statistics for selected areas of the United States, and these statistics are intended to be representative of the entire population of the continental United States (12). We obtained SEER mortality rates for biliary cancer [ICD (eighth revision) codes 155.5, 156.1-156.9)] for the years 1973-1977. We used these data to estimate the number of deaths expected from biliary cancer while controlling for the effects of age, race, and sex. We could not control for the effect of calendar period because mortality rates for biliary cancer were unavailable for the 1950 s and 1960 s. For the three deaths from biliary cancer in the cohort, we computed an estimate of 0.15 expected deaths (SMR $20,95 \%$ CI 5.2-56).

\section{Discussion}

We identified 122 deaths in an occupational cohort exposed to methylene chloride in the production of cellulose triacetate fiber. Since we did not verify the vital status of the 1149 employees not identified as deceased, we may have underestimated the total number of deaths in the cohort. Studies have shown that the national death index and the records of the Social Secu- rity Administration may fail to ascertain mortality by approximately $10-20 \%(7,8)$.

For most causes of death, the results do not indicate an effect of exposure. In particular, this cohort experienced no excess mortality from ischemic heart disease, which is in agreement with the results reported for a cohort of photographic film manufacturers (4). Thus, within the limits of these two studies, any reduction in arterial oxygen content caused by methylene chloride being metabolized to carbon monoxide does not appear to have an adverse effect on mortality from ischemic heart disease.

Our study did not corroborate the association between methylene chloride exposure and death from pancreatic cancer that was found earlier for the photographic film manufacturers (4). Seven of the eight deaths from pancreatic cancer observed among the photographic film manufacturers occurred, however, more than 30 years after first employment. In our textile cohort only about $6 \%$ of the total person-time was contributed by workers for whom at least 30 years had elapsed since first employment. This cohort, therefore, has not yet been followed long enough to be informative about exposure-disease relations with induction periods as long as 30 years. For this reason, the absence of a pancreatic cancer excess in this cohort is not inconsistent with the findings from the cohort of photographic film manufacturers.

We observed an excess of approximately three deaths from cancer of the biliary tract. Biliary cancer has not been previously reported to be associated with exposure to methylene chloride, acetone, or methanol. Bioassays have shown, however, that the inhalation of $2000 \mathrm{ppm}$ of methylene chloride over a period of two years produces lung and liver tumors in mice and mammary tumors in rats $(1,3)$. Included among the nonneoplastic effects on the rats was fibrosis of the biliary tract (3). There is little information with which to compare the pharmacokinetics of methylene chloride in the biliary tracts of rats with that in the biliary tracts of humans. Thus the implications of the bioassays for the potential carcinogenicity of methylene chloride in the human biliary tract are unclear.

A study of Swedish painters revealed excess cancer of the intrahepatic bile ducts (13), and an excess of biliary cancer also has been reported for rubber workers (14). These cohorts were exposed to many solvents, however, and the results are difficult to interpret with regard to the effects of specific agents.

In the most recent follow-up of the cohort of photographic film manufacturing workers, Hearne et al (4) found no deaths from cancer of the liver or biliary tract ( 0.8 deaths were expected for these sites combined on the basis of New York State death rates) (T Hearne, personal communication). Eastman Kodak researchers are currently verifying the cause of death for all digestive cancers recorded for this cohort. The methylene 
chloride exposures of the present study population appeared to have been considerably higher than the exposure levels experienced by the photographic film manufacturers, whose exposure was reported to average $26 \mathrm{ppm}$ (TWA) over 22 years (4). If methylene chloride causes biliary tract cancer, it may do so at levels of exposure experienced by the cohort of textile production workers but not at the levels experienced by the cohort of photographic film workers. Another important difference between these cohorts is that the photographic film manufacturers were all men, whereas our cohort of textile workers was mostly women. Two of the biliary cancer decedents in this study were women. In this regard, a recent study revealed an association between solvent exposure and biliary cancer in women but not in men (15).

The excess deaths from bile duct cancer in our cohort might have been caused by other risk factors for these cancers. But biliary cancer has not been the subject of much study, and few risk factors have been identified. The use of oral contraceptives is associated with liver tumors (16), and there have been two reports of biliary cancer in women aged 21 and 29 years with a recent history of oral contraceptive use $(17,18)$. Oral contraceptive use is common among young women, however, and a possible relation between oral contraceptives and biliary cancer has not been studied epidemiologically. Two of the three deaths from biliary cancer in this cohort occurred in women; their ages (47 and 60 years), however, are not typically associated with recent use of oral contraceptives. It is possible that, if oral contraceptives cause biliary cancer, they do so only after a long induction period; the case reports, however, would suggest otherwise. Cancer of the bile ducts is associated with a medical history of chronic ulcerative colitis and gallstones (19), but neither of these factors was noted in the medical records.

In this cohort the excess deatins from accidental causes were of interest in light of the neurobehavioral effects of methylene chloride (20). This study did not take into account the effects of many other risk factors for accidental death (eg, alcohol consumption, amount of automobile driving, etc), however, and cannot be assumed to measure accurately the effect of methylene chloride on accidental deaths.

In summary, we did not observe a previously reported excess of mortality from pancreatic cancer (4). If methylene chloride causes pancreatic cancer, it may do so after long induction times not yet experienced by this cohort. The strongest association observed in this study was an excess of mortality from cancer of the bile ducts, an association that was not observed in a study made in the photographic industry (4). If the excess of cancer of the bile ducts is a direct result of methylene chloride exposure, then the absence of such an excess in the study by Hearne et al (4) may indicate a threshold dose below which there is no effect.

\section{Acknowledgments}

We extend our sincere appreciation to Ms L Wilson, Ms C Lowery, Mr N Culbertson, and Mr M Parent for their assistance in obtaining plant records and explaining plant operations, and to the Dow Chemical Company for providing a data tape of the cohort and related documentation without which this study would not have been possible.

This study was supported by funds provided by the Hoechst Celanese Corporation. The conclusions expressed in this article do not necessarily reflect those of Hoechst Celanese or the Dow Chemical Company.

\section{References}

1. United States Environmental Protection Agency. Health assessment document for dichloromethane (methylene chloride). Research Triangle Park, NC: United States Environmental Protection Agency, 1985. (Final report PB85-191559.)

2. Stewart RD, Fisher TN, Hosko MJ, Peterson JE, Baretta ED, Dodd HC. Experimental human exposure to methylene chloride. Arch Environ Health 1972;25:342-8.

3. Mennear JH, McConnell EE, Huff JE, Renne RA, Giddens $\mathrm{E}$. Inhalation toxicology and carcinogenesis studies of methylene chloride in $\mathrm{F} 344 / \mathrm{N}$ rats and $\mathrm{B} 6 \mathrm{C} 3 \mathrm{~F}_{1}$ mice. Ann NY Acad Sci 1988;534:343-51.

4. Hearne FT, Grose F, Pifer JW, Friedlander BR, Raleigh RL. Methylene chloride mortality study: dose response characterization and animal comparison. J Occup Med 1987;29:217-28.

5. Ott MG, Skory LK, Holder BB, Bronson JM, Williams PR. Health evaluation of employees occupationally exposed to methylene chloride. Scand J Work Environ Health 1983;9(suppl 1):38 p.

6. Williams PR, Bronson JM, Rapp DE, Skory L. A comprehensive industrial hygiene survey for exposure to airborne methylene chloride, methanol and acetone vapors, oil mist and carbon monoxide concentrations, at the Celanese Fibers Company, Celco plant, Narrows West Virginia, and Celriver plant, Rock Hill, South Carolina, from September, 1977 to February, 1978. Midland, MI: Dow Chemical Company, 1978.

7. Wentworth DN, Neaton JD, Rasmussen WL. An evaluation of the Social Security Administration master beneficiary record file and the National Death Index in the ascertainment of vital statistics. Am J Public Health $1983 ; 73: 1270-4$.

8. Curb JD, Ford CE, Pressel S, Palmer M, Babcock C, Hawkins CM. Ascertainment of vital status through the National Death Index and the Social Security Administration. Am J Epidemiol 1985;121:754-66.

9. World Health Organization. Manual of the international classification of diseases; vol 1. 9th ed. Ann Arbor, MI: Commission on Professional and Hospital Activities, 1977.

10. Marsh GM, Preininger M. OCMAP: a user-oriented occupational cohort mortality analysis program. Am Stat 1980;34:245.

11. Miettinen OS. Comment. J Am Stat Assoc 1974;69: 380-2.

12. National Institutes of Health. Surveillance, epidemiology and end results incidence and mortality data, 1973-77. Bethesda, MD: National Cancer Institute, 1981. (Monograph; no 57.)

13. Engholm G, Englund A. Cancer incidence and mortality among Swedish painters. In: Englund A, Ringen K, Mehlman MA, ed. Occupational health hazards of sol- 
vents. Princeton, NJ: Princeton Scientific Publishers Inc, 1982;173-85.

14. Mancuso TF, Brennan MJ. Epidemiological considerations of cancer of the gallbladder, bile ducts and salivary glands in the rubber industry. J Occup Med 1970; $12: 333-41$.

15. Hernberg $\mathrm{S}$, Kauppinen $\mathrm{T}$, Riala $\mathrm{R}$, Korkala $\mathrm{M}-\mathrm{L}$, Asikainen U. Increased risk for primary liver cancer among women exposed to solvents. Scand J Work Environ Health 1988;14:356-65.

16. Falk H. Liver. In: Schottenfeld D, Fraumeni JF, ed. Cancer epidemiology and prevention. Philadelphia, PA: WB Saunders and Company, 1982;668-82.

17. Ellis EF, Gordon PR, Gottlieb LS. Oral contraceptives and cholangiocarcinoma [Letter to the editor]. Lancet 1978;1:207.
18. Littlewood ER, Barrison IG, Murray-Lyon IM, et al. Cholangiocarcinoma and oral contraceptives [Letter to the editor]. Lancet 1980;1:309-10.

19. Fraumeni JF, Kantor AF. Biliary tract. In: Schottenfeld D, Fraumeni JF, ed. Cancer epidemiology and prevention. Philadelphia, PA: WB Saunders and Company, 1982;683-91.

20. National Institute for Occupational Safety and Health. Criteria for a recommended standard: occupational exposure to methylene chloride. Washington, DC: Department of Health, Education and Welfare, 1976:65-8. (Publication no (NIOSH) 76-138.)

Received for publication: 30 October 1989 